\title{
The Theory and Practice of Political Freedom in Interdisciplinary Perspective: Introduction ${ }^{1}$
}

\author{
Katarzyna Eliasz \\ Jagiellonian University, Cracow, Poland \\ katarzyna.eliasz@uj.edu.pl
}

In Freedom: A New Analysis, Maurice Cranston aptly characterised 'freedom' as a 'hurrah-word' (Cranston, 1954, p. 16), by which he meant that it would be admittedly difficult to point at circumstances in which evoking it elicits negative associations. Arguably, freedom's capacity to bring out positive connotations is one of its few unambiguous properties, for the concept of freedom has numerous meanings and refers to a variety of markedly different phenomena. The distinction between a negative and positive freedom, deeply embedded in political thought and captured by Isaiah Berlin in his famous essay, relates only to some of the many meanings of freedom, even though the definitions are broad enough to accommodate a plethora of significantly different philosophical standpoints. It is especially so in the case of the positive concept, according to which freedom is understood as self-mastery (cf. Berlin, 2000, p. 203; Taylor, 1985, p. 213). The internal diversity of the positive concept becomes clearly apparent when one compares the views of its most prominent representatives, e.g. Rousseau, Nietzsche, Plato, or the stoics. In addition, in contemporary debates a new concept of freedom, irreducible to the former two, has gained attention mainly within the republican political theory. Its adherents argue that freedom amounts to the state of non-domination understood as absence of both the actual and the potential arbitrary interference from either the state authority or other people (cf. Lovett, 2010, p. 119; Pettit, 1997, pp. 21-27). In this respect, it differs significantly from the negative concept, according to which any interference (arbitrary or not) is an infringement of freedom. Now, the negative freedom and non-domination both entail the

\footnotetext{
${ }^{1}$ The following issue of Avant. Trends in Interdisciplinary Studies was prepared as part of the research grant "The Place of Political Freedom in the Hierarchy of Democratic Values", founded by the National Science Centre, Poland, on the basis of the decision DEC-2016/23/D/HS5/01814.
} 
assumption that freedom is experienced in the private sphere (although the proponents of non-domination emphasise the importance of legal and political institutions in securing it), which means that one can enjoy it regardless of their political engagement. Against this background, political freedom in the strict sense is a public freedom. It amounts to being a participator in government through the process of choosing and controlling public administration. As Friedrich August von Hayek puts it:

It derives from an application of our concept [i.e. freedom] to groups of men as a whole which gives them a sort of collective liberty. But a free people in this sense is not necessarily the people of free men; nor need one share in this collective freedom to be free as an individual. (von Hayek, 2011, pp. 61-62)

It may be trivial to say that a well-balanced democracy requires an interplay of these two (public and private) kinds of freedom. And yet, their precise meaning and scope-all the more so the question of supporting and promoting them - is far from obvious. The contributions collected in this issue of Avant attempt to address some of these problems. At this point it is crucial to underline that the question of promoting the private and public freedom is far from being a merely scholarly enterprise. In his latest book, Yasha Mounk argued tellingly that finding a proper balance between them might protect liberal democracy from being transformed into either illiberal democracy or undemocratic liberalism. According to Mounk:

If we have to give up on either individual rights or the popular will, we are being asked to make an impossible choice. [...] It is looking increasingly doubtful that either illiberal democracy or undemocratic liberalism will turn out to be especially stable. A system that dispenses with individual rights in order to worship at the altar of the popular will may ultimately turn against the people. Conversely, a system that dispenses with the popular will in order to protect individual rights may ultimately have to resort to increasingly blatant repression to quell dissent. (Mounk, 2018, p. 97)

The contributions collected in this volume of Avant analyse the multi-faceted question of the relationship between politics and freedom from the interdisciplinary perspective. They draw on various fields of knowledge, e.g. philosophy, political studies, law and legal theory, psychology, and philosophical anthropology.

The issue has been divided into three sections. The first one is devoted to the analysis of the philosophical foundations of political freedom (the papers by Wojciech Załuski, Katarzyna Eliasz, Anna Budzanowska and Tomasz Pietrzykowski). The second section addresses the relationship between freedom and democracy (it includes papers by Karol Chrobak, Justyna Miklaszewska, Michał Zabdyr-Jamróz, and Alessandro Serpe). The last section analyses the problem of freedom from the perspective of law and legal philosophy (contributions by Tomasz Bekrycht, Szymon Osmola, and Szymon Mazurkiewicz).

In the first paper published in this volume, Wojciech Załuski analyses the psychological links between the active and the contemplative life from the twofold perspective: he discusses the psychological mechanisms which predispose one to discard one type of life in favour of another, and analyses the positive motivational influence of vita contemplativa 
on vita activa. Against stereotypical views, he argues that vita contemplativa (especially in its strong, i.e. metaphysically-oriented form) enforces the involvement in the public vita activa. According to the Author, the main components of vita contemplativa, i.e. selflessness and otherworldliness, support the effectiveness and durability of public action.

Wojciech Załuski's enquiries into the psychological relations between vita contemplativa and vita activa allow him to formulate axiological conclusions concerning the superiority of vita contemplativa over vita activa, since - as he argues - the former is less prone to disappointment than the latter.

The article by Katarzyna Eliasz is devoted to the analysis of the structure of the concept of political freedom as presented in the works of Hannah Arendt. The Author demonstrates that the Arendtian concept incorporates two pre-political concepts of freedom, i.e. freedom as spontaneity and freedom as exercising action. Through investigating the complexities of Arendt's account of political freedom, Katarzyna Eliasz exposes the anthropological justification for the distinguished position of political freedom (as understood by Arendt) in the hierarchy of democratic values. Arendt's insistence on a distinguished significance of political freedom propelled her towards criticising representative democracy (as a system which narrows down the scope of political freedom) and proposing an alternative account of political system, one that is based on councils. Katarzyna Eliasz argues that, contrary to Arendt's claim, such a system would presumably fail to accommodate the demanding ideal of political freedom, which she advocated.

Anna Budzanowska and Tomasz Pietrzykowski discuss the impact of intellectual debates in France in the period between the Revolution of 1789 and the Dreyfus Affair regarding the key concepts of modern political culture. The Authors reveal that the Revolution initiated ideological debates, which gave rise to two markedly distinct political conceptions, i.e. counterrevolutionary conservatism and progressive republicanism. Anna Budzanowska and Tomasz Pietrzykowski demonstrate that the divide between religious, conservative right, and secular progressive left was clearly apparent in the context of the Dreyfus Affair. The Dreyfusards honoured individual liberty and appealed for the constraint of governmental arbitrary power, whereas their opponents exposed distrust towards individual liberty, which they perceived as a potential threat to the collective spirit of the political community. According to the Authors, the credibility of the conservative standpoint shared by antiDreyfusards was significantly impaired once the governmental conspiracy to hide evidence of Dreyfus's innocence saw the light of the day. Moreover, they indicate that the distrust of adherents of the conservative standpoint towards individual liberty as the source of excessive individualism, isolation, and social disintegration appears to be unsubstantiated.

The article by Karol Chrobak analyses the causes underlying the contemporary crisis of liberal democracy. The Author asserts that the sources of this crisis lie in citizens' reluctance towards political participation. According to him, a decreasing willingness to exercise political freedom results from two varieties of social polarisation: the vertical polarisation (occurring between the rulers and the ruled) and the horizontal polarisation (occurring between the citizens). The former one is typical of post-democracies, while the latter one 
occurs mainly in illiberal democracies. Yet, as Karol Chrobak indicates, both varieties can occur simultaneously within one democratic order. In the case of the vertical polarisation, the citizens renounce political activities based on the conviction that their actions are deprived of significance. The horizontal polarisation occurs when the public sphere is appropriated by opposing ideological camps, in which case the majority of moderate political standpoints lack recognition. The Author sees the solution to the two kinds of polarisation (and, thereby, to the crisis of democracy) in an open and inclusive public sphere. Drawing on Chantal Mouffe's and Helmuth Plessner's investigations, Karol Chrobak asserts that a radically open and, as he writes, sometimes chaotic and uneasy public realm would allow political freedom to fulfil both its political and anthropological functions.

In her paper, Justyna Miklaszewska analyses threats that the freedom of speech might pose to democracy. She argues that this core liberal freedom may, in fact, undermine liberal democracy when exercised under the influence of propaganda or in the attempt to disseminate it. The Author reveals that the prerequisites of freedom of speech, i.e. freedom of thought and choice, are nowadays under greater danger of being constrained than ever before due to the development of unreliable sources of information, in particular social media. Justyna Miklaszewska maintains that safeguarding liberal democracy from the prospective negative effects of untruthful information justifies the potential limitations to the freedom of speech, which should not amount to mere ethical self-constraint, but should also encompass additional legal measures to be imposed on those who spread false information deliberately. Such restrictions are justified by the vital role that the freedom of speech performs in the contemporary political culture. It can be a condition of a meaningful public debate and a means to maintaining the democratic political culture. On the other hand, once unrestricted, the freedom of speech could contribute to greater social polarisation, and, as a result, the destruction of the process of public decision-making.

According to Michał Zabdyr-Jamróz, the condition of a meaningful participation in government is the citizens' capacity to formulate and understand the available policy options. In order to meet these requirements, the citizens should engage in deliberation, which the Author defines as encompassing the deliberative stance, i.e. the openness to changing a preference in the course of deliberation. Michał Zabdyr-Jamróz analyses various factors behind what he calls the atrophy of the deliberative stance, i.e. the unwillingness to change one's views upon arguments relating to the general interests, but the readiness to change them due to the calculation of a personal (self-interested) gain. The Author considers factors behind such an atrophy and demonstrates that they result from actual roles that political actors take in deliberation. He argues that atrophy is most likely to occur when they act as representatives, act facing the audience, or acknowledge that their decisions will have binding and profound consequences (decisional atrophy of deliberative stance). Michał Zabdyr-Jamróz indicates that, in order to prevent this atrophy, deliberative minipublics should not have the power to arrive at formally binding decisions. The Author develops the Open Siege of Alesia Model of deliberation, and argues that it can remedy the challenges facing the deliberative stance. 
In his article, Alessandro Serpe examines whether the ethics of care could provide a support for democracy through contributing to its greater justice. He seeks to answer this question by collating the concepts of care and needs with justice and rights. Alessandro Serpe argues that the interplay of care and justice constitutes a convincing alternative to the unilateral account of moral reasoning (i.e. focused on justice), although, as he claims, providing such an interplay does not require substituting the liberal perspective with care ethics. In a similar vein, the Author argues against substituting the language of rights with the language of needs within the democratic practice. His analysis leads him to the conclusion that realising liberal values is sufficient for attaining a society that is respectful of its citizens' needs as well as for pursuing the common good. Therefore, from the perspective of significance for democratic theory, the ethics of care, as the Author argues, shows its feet of clay.

Tomasz Bekrycht's paper is devoted to the analysis of the Kantian transcendental argument for the sovereignty of community, and to exposing how Kant reconciled freedom and coercion within the framework of positive law. Following Kant, the Author indicates that human beings are to be perceived as, on the one hand, autonomous moral subjects and, on the other, as objects, since they exist alongside other people and have a capacity to affect them. Therefore, people should act in accordance with the categorical imperative of universal legislation, i.e. a maxim that could be translated into a general law. Tomasz Bekrycht draws attention to the ambiguity of this formulation, indicating that a closer scrutiny allows one to differentiate between: subjective (individual) morality, intersubjective (communal) morality, and positive law (the condition of realising binding moral rules). The legal coercion is justified when one's use of freedom cannot be reconciled with the freedom in accordance with universal laws of another subject. In such cases, freedom is compatible with the existence of coercion. Tomasz Bekrycht reveals that the Kantian approach to freedom is reminiscent of the ancient one. The account of the community advocated by Kant approximates the ancient vision of the public sphere, in which human beings were treated as rational, equal, and free subjects.

Szymon Osmola aims at reconciling the basic principles of contract law, i.e. the freedom of contract and corrective justice, with policy goals implemented in the contract law of the European Union (which encompasses various regulations that limit the scope of the freedom of contract). Against the views which assume that the EU contract law is inconsistent with the leading theories of contract law, the Author argues that some of the autonomy theories within contract law can be adjusted so that they match the EU regulations. He differentiates between the strong and the moderate conceptions of corrective justice, and argues that while the former cannot be reconciled with the EU contract law, the latter can be adjusted so that it is consistent with it. Szymon Osmola argues that, in order to provide such compatibility, the concept of harm (central to the theory of corrective justice) should be understood broadly, i.e. it should accommodate a variety of harms within the EU contract law. The Author claims that although enlisting unfair practices in contract law limits the freedom of contract, it is compatible with liberalism, since liberalism enables the constriction of the freedom of contract for the sake of enhancing other personal freedoms. 
Szymon Mazurkiewicz's contribution deals with the logical paradox which emerged in the context of the ruling passed by the Polish Constitutional Tribunal on March $9^{\text {th }}, 2016$. The ruling in question concerned the constitutionality of the amendment of the Constitutional Tribunal Act, enacted on December $22^{\text {nd }}, 2015$. Due to the absence of vacatio legis, the challenged provisions of the amendment were both the subject of review and its legal basis. This troublesome situation was labeled as the verdict paradox and considered by some scholars to be a specific case of the well-known liar paradox. This interpretation provides a justification for CT's decision not to take into account the challenged provisions and examine the amendment's constitutionality based on the Constitution. Now, relying on the abstract (logical) analysis and the concrete (legal) analysis, Szymon Mazurkiewicz provides an alternative interpretation of the verdict paradox. He argues that although the verdict paradox is not the liar paradox, a logical analysis justifies the CT's decision to pass over the challenged provisions. The Author indicates that the reasoning he advocates should be considered as an instance of how logical reasoning contributes to safeguarding institutions that are crucial from the perspective of securing political freedoms. Ultimately, the rule of law secured by the $\mathrm{CT}$ is supposed to perform this vital democratic function.

The papers collected in this volume relate to various aspects of the complex relationships between freedom, politics, and the law, and draw on many fields of knowledge. I hope that this diversity will allow anyone interested in this central legal, political, and philosophical problem to gain an inspiring and thought-provoking perspective.

I would like to thank Wojciech Załuski for his help in editing this volume.

\section{References}

Berlin, I. (2000). Two Concepts of Liberty. In The Proper Study of Mankind (pp. 191-242). New York, NY: Farrar, Straus and Giroux.

Cranston, M. (1954). Freedom: A New Analysis. London, UK: Longmans, Green.

Lovett, F. (2010). A General Theory of Domination and Justice. Oxford, UK: Oxford University Press.

Mounk, Y. (2018). The People vs. Democracy: Why Our Freedom is in Danger and How to Save It. Cambridge, MA: Harvard University Press.

Pettit, P. (1997). Republicanism: A Theory of Freedom and Government. Oxford, UK: Clarendon Press.

Taylor, Ch. (1985). What's Wrong With Negative Liberty. In Philosophy and the Human Sciences. Philosophical Papers (Vol. 2, pp. 211-229). Cambridge, UK: Cambridge University Press.

von Hayek, F. A. (2011). The Constitution of Liberty. Chicago, IL: The University of Chicago Press. 